Pacific Journal of Mathematic 


\title{
ITERATIVE TECHNIQUES FOR APPROXIMATION OF FIXED POINTS OF CERTAIN NONLINEAR MAPPINGS IN BANACH SPACES
}

\author{
R. L. THELE
}

Let $D$ be a closed convex subset of a Banach space $X$, let $T: D \rightarrow D$ be nonexpansive (that is, $\|T x-T y\| \leqq\|x-y\|$ for every $x, y \in D)$, and let $F_{\lambda}=\lambda T+(1-\lambda) I$, where $\lambda \in(0,1)$ and $I$ denotes the identity on $D$. Several authors have found conditions under which the sequences of iterates $\left\{T^{n} x\right\}$, or the sequences $\left\{F_{\lambda}^{n} x\right\}$, converge strongly or weakly to fixed points of $T$ for all $x \in D$. In this paper we establish conditions under which the sequences $\left\{F_{1 / 2}^{n} x\right\}$ converge strongly to fixed points of $T$ for all $x$ in a neighborhood of the fixed point set of $T$; furthermore, our theorems hold for classes of mappings $T$ more general than the class of nonexpansive mappings.

We complement these results by proving theorems under which local convergence of iterates entails global convergence; thus by combining our results in these two areas we obtain new theorems regarding the global convergence of iterates. Finally, we give an example of a class of mappings satisfying the various conditions of our theorems.

1. Local and global convergence of iterates. Let $D$ be a convex subset of the Banach space $X$, and let $T: D \rightarrow D$. Adopting the terminology of Furi and Vignoli [6] we say that the sequence $\left\{T^{n} x_{0}\right\}$ of iterates of $x_{0} \in D$ is stable if for every $\varepsilon>0$ there exists $\delta>0$ such that $\left\|T^{n} x-T^{n} x_{0}\right\|<\varepsilon$ for every $n=1,2, \cdots$ whenever $x \in D$ and $\left\|x-x_{0}\right\|<\delta$. We say that $T$ has stable iterates if the sequence $\left\{T^{n} x\right\}$ of iterates of $x$ is stable for every $x \in D$. Finally, if $x \in X$ and $B \subset X$ we define $d(x, B)=\inf \{\|x-y\|: y \in B\}$.

THEOREM 1. Let $D$ be a convex subset of a Banach space $X$ and suppose that $T: D \rightarrow D$ has stable iterates. Let $A$ be a nonempty subset of $D$.

(i) If there exists $\rho>0$ such that $\left\{T^{n} x\right\}$ has a cluster point in $A$ whenever $x \in D$ and $d(x, A)<\rho$, then $\left\{T^{n} x\right\}$ has a cluster point in $A$ for every $x \in D$.

(ii) If there exists $\rho>0$ such that $\left\{T^{n} x\right\}$ has its limit in $A$ whenever $x \in D$ and $d(x, A)<\rho$, then $\left\{T^{n} x\right\}$ converges to some point of $A$ for every $x \in D$.

Proof. To prove the first statement, let $x \in D$ and $x_{0} \in A$. For 
each $\lambda \in[0,1]$ let $y_{\lambda}=\lambda x+(1-\lambda) x_{0}$ and set $\lambda_{0}=\sup \left\{\lambda \in[0,1]:\left\{T^{n} y_{\lambda}\right\}\right.$ has a cluster point in $A\}$. Let $\delta$ correspond to $\varepsilon=\rho / 3$ in the definition of the stability of $\left\{T^{n} y_{\lambda_{0}}\right\}$, and choose $\lambda_{1} \in\left[0, \lambda_{0}\right]$ such that $\left\|y_{\lambda_{1}}-y_{\lambda_{0}}\right\|<\delta$ and $\left\{T^{n} y_{\lambda_{1}}\right\}$ has a cluster point in $A$. If $\lambda_{0}=1$, let $\lambda_{2}=\lambda_{0}$; if $\lambda_{0}<1$, let $\lambda_{2} \in\left(\lambda_{0}, 1\right]$ be such that $\left\|y_{\lambda_{2}}-y_{\lambda_{0}}\right\|<\delta$. Since there exists a cluster point $w$ in $A$ of $\left\{T^{n} y_{\lambda_{1}}\right\}$ and a positive integer $N$ such that $\left\|T^{N} y_{\lambda_{1}}-w\right\|<\rho / 3$, we have that

$$
\begin{aligned}
\left\|T^{N} y_{\lambda_{2}}-w\right\| & \leqq\left\|T^{N} y_{\lambda_{2}}-T^{N} y_{\lambda_{0}}\right\|+\left\|T^{N} y_{\lambda_{1}}-T^{N} y_{\lambda_{0}}\right\|+\left\|T^{N} y_{\lambda_{1}}-w\right\| \\
& <\rho / 3+\rho / 3+\rho / 3=\rho .
\end{aligned}
$$

Thus $d\left(T^{N} y_{\lambda_{2}}, A\right) \leqq\left\|T^{N} y_{\lambda_{2}}-w\right\|<\rho$, entailing that $\left\{T^{N+n} y_{\lambda_{2}}\right\}$-and hence $\left\{T^{n} y_{\lambda_{2}}\right\}$-has a cluster point in $A$. If $\lambda_{0}<1$, this contradicts the definition of $\lambda_{0}$; thus $\lambda_{0}=1$, and since in this case $y_{\lambda_{2}}=x$, we have that $\left\{T^{n} x\right\}$ has a cluster point in $A$.

To prove the second statement, we let $x \in D$ and note that by our proof of the first statement $\left\{T^{n} x\right\}$ has a cluster point $w \in A$. Thus there exists a positive integer $N$ such that $\left\|T^{N} x-w\right\|<\rho$, implying that $T^{N+n} x \rightarrow w$, whence $T^{n} x \rightarrow w$.

We remark that in the case of the second statement of the theorem above, $A$ must contain a fixed point of $T$, since if $T$ is continuous the limit of a sequence $\left\{T^{n} x\right\}$ is necessarily a fixed point. In our applications of this theorem we will assume either that $A$ is the fixed point set of $T$ or that $A$ is a singleton.

Corollary 1. Let $D$ be a convex subset of a Banach space $X$, and let $T: D \rightarrow D$ possess stable iterates. Let $x_{0}$ be a fixed point of $T$ for which there exists an open neighborhood $U$ of $x_{0}, U \subset D$, such that $T$ is continuously Fréchet differentiable in $U$ and $\left\|T^{\prime} x_{0}\right\|<1$. Then $T^{n} x \rightarrow x_{0}$, for every $x \in D$.

Proof. Since $T$ is continuously Fréchet differentiable in $U$ and $\left\|T^{\prime} x_{0}\right\|<1$, there exists a constant $k \in(0,1)$ and an open ball $S\left(x_{0}, \rho\right)$ about $x_{0}$ with radius $\rho, S\left(x_{0}, \rho\right) \subset U$, such that if $x \in S\left(x_{0}, \rho\right)$ then $\left\|T^{\prime} z\right\|<k$. Let $y \in S\left(x_{0}, \rho\right)$. Then there exists a point $z$ in the segment from $x_{0}$ to $y$ such that (see Fréchet [5])

$$
\left\|T x_{0}-T y\right\| \leqq\left\|T^{\prime} z\right\|\left\|x_{0}-y\right\| \text {. }
$$

But $z \in S\left(x_{0}, \rho\right)$ so that $\left\|T^{\prime} z\right\|<k$. Thus for every $y \in S\left(x_{0}, \rho\right)$

$$
\left\|T x_{0}-T y\right\| \leqq k\left\|x_{0}-y\right\| \text {. }
$$

By induction, $\left\|x_{0}-T^{n} y\right\| \leqq k^{n}\left\|x_{0}-y\right\|$ for every $n=1,2,3, \cdots$. Since $k^{n} \rightarrow 0, T^{n} y \rightarrow x_{0}$ for every $y \in S\left(x_{0}, \rho\right)$. By part (ii) of Theorem $1, T^{n} x \rightarrow x_{0}$ for every $x \in D$. 
2. Conditions implying local convergence of iterates. The modulus of convexity of a Banach space $X$ is the function $\delta:[0,2] \rightarrow$ $[0,1]$ defined by

$$
\delta(\varepsilon)=\inf \left\{1-\frac{1}{2}\|x+y\|:\|x\| \leqq 1,\|y\| \leqq 1 \text {, and }\|x-y\| \geqq \varepsilon\right\} .
$$

It is well-known (cf. [9]) that $\delta$ is nondecreasing and continuous except possibly at 2 . Furthermore, letting $\varepsilon_{0}=\sup \{\varepsilon \in[0,2]: \delta(\varepsilon)=0\}$, $X$ is uniformly convex if and only if $\varepsilon_{0}=0, X$ is uniformly nonsquare if and only if $\varepsilon_{0}<2$, and $X$ is strictly convex if and only if $\delta(2)=1$.

We observe that if $x, y \in X$ satisfy the conditions

$$
\begin{gathered}
\|x\| \leqq d,\|y\| \leqq d, \text { and }\|x-y\| \geqq \varepsilon, \text { then } \\
\left\|\frac{x+y}{2}\right\| \leqq\left(1-\delta\left(\frac{\varepsilon}{d}\right)\right) d .
\end{gathered}
$$

Finally, we denote by $I$ the identity mapping on any convex subset of $X$.

THEOREM 2. Let $D$ be a convex subset of a uniformly nonsquare Banach space $X$. Suppose that $T: D \rightarrow D$ has a nonempty fixed point set $A$ and that $T$ satisfies the following conditions: There exist $\rho>0, c>0$, and $s \geqq 1$ with $(1-\delta(c / s)) s<1$ such that if $x \in D$ and $d(x, A)<\rho$ then

(i ) $\|T x-x\| \geqq c d(x, A)$, and

(ii) $\|T x-u\| \leqq s\|x-u\|$ for every $u \in A$.

Then setting $F=1 / 2(I+T), d\left(F^{n} x, A\right) \rightarrow 0$ for every $x \in D$ for which $d(x, A)<\rho$.

Proof. We observe that if $x \notin A$ then

$$
c d(x, A) \leqq\|T x-x\| \leqq\|T x-u\|+\|x-u\| \leqq(1+s)\|x-u\|
$$

for every $u \in A$. Thus $c d(x, A) \leqq(1+s) d(x, A)$, so that if $T$ is not the identity then $c \leqq 1+s$. Therefore $c / s \leqq 1+1 / s \leqq 2$, and moreover if $c / s=2$, then $s=1$ and $c=2$.

Let $x \in D$ satisfy $0<d(x, A)<\rho$, and for arbitrary $r>1$ let $u_{x, r} \in A$ satisfy $\left\|x-u_{x, r}\right\| \leqq$ minimum $\{\rho, r d(x, A)\}$. Thus $\left\|T x-u_{x, r}\right\| \leqq$ $s\left\|x-u_{x, r}\right\|$.

Let $d=s\left\|x-u_{x, r}\right\|$ and $\varepsilon=\|T x-x\|$. Since $\left\|x-u_{x, r}\right\| \leqq d$, $\left\|T x-u_{x, r}\right\| \leqq d$, and $\left\|\left(x-u_{x, r}\right)-\left(T x-u_{x, r}\right)\right\|=\varepsilon$ we obtain

$$
\begin{aligned}
\left\|F x-u_{x, r}\right\| & =\frac{1}{2}\left\|\left(x-u_{x, r}\right)+\left(T x-u_{x, r}\right)\right\| \\
& \leqq(1-\delta(\varepsilon / d)) d .
\end{aligned}
$$


Now

$$
\frac{\varepsilon}{d}=\frac{\|T x-x\|}{s\left\|u_{x, r}-x\right\|} \geqq \frac{c d(x, A)}{\operatorname{srd}(x, A)}=\frac{c}{s r},
$$

and thus since $\delta$ is nondecreasing

$$
1-\delta(\varepsilon / d) \leqq 1-\delta\left(\frac{c}{s r}\right)
$$

Therefore,

$$
\begin{aligned}
& d(F x, A) \leqq \\
&\left(F x-u_{x, r} \| \leqq(1-\delta(\varepsilon / d)) d \leqq\left(1-\delta\left(\frac{c}{s r}\right)\right) d\right. \\
&=\left(1-\delta\left(\frac{c}{s r}\right)\right) s\left\|x-u_{x, r}\right\| \leqq\left(1-\delta\left(\frac{c}{s r}\right)\right) \operatorname{srd}(x, A),
\end{aligned}
$$

for every $r>1$.

Let $\eta \equiv \lim _{r \rightarrow 1+}(1-\delta(c / s r)) s r$. Then $d(F x, A) \leqq \eta d(x, A)$ whenever $d(x, A)<\rho$. If $c / s<2$ then $\delta$ is continuous at $c / s$ and $\eta=$ $(1-\delta(c / s)) s<1$. If $c / s=2$ then $c=2$ and $s=1$, and since $X$ is uniformly nonsquare, $\eta=1-\lim _{\varepsilon \rightarrow 2-} \delta(\varepsilon)<1$. By induction, $d\left(F^{n} x, A\right) \leqq$ $\eta^{n} d(x, A)$ whenever $d(x, A)<\rho$, implying that $d\left(F^{n} x, A\right) \rightarrow 0$ whenever $d(x, A)<\rho$.

COROLlary 2. If the hypotheses of Theorem 2 are satisfied and if in addition $A$ is compact, then the sequence $\left\{F^{n} x\right\}$ has a cluster point in $A$ whenever $d(x, A)<\rho$.

Proof. Since whenever $d(x, A)<\rho$ we have $d\left(F^{n} x, A\right) \rightarrow 0$, we can select a sequence $\left\{a_{n}\right\} \subset A$ such that $\left\|F^{n} x-a_{n}\right\| \rightarrow 0$. The sequence $\left\{a_{n}\right\}$ has a cluster point $a \in A$ which is then a cluster point of $\left\{F^{n} x\right\}$.

We note two important consequences of Theorem 2:

REMARK 1. If the mapping of Theorem 2 (or Corollary 2) has a unique fixed point $u$ then one may conclude that $F^{n} x \rightarrow u$ for every $x \in D$ for which $\|x-u\|<\rho$.

REMARK 2. If condition (ii) of Theorem 2 holds for $s=1$ and if $X$ is uniformly nonsquare then one need only verify that condition (i) holds for some $c \in\left(\varepsilon_{0}, 2\right]$.

By applying Theorem 1 to Corollary 2 we obtain:

COROLlary 3. If the hypotheses of Theorem 2 are satisfied, and 
if in addition $A$ is compact and $F$ has stable iterates, then the sequence $\left\{F^{n} x\right\}$ has a cluster point in $A$ for every $x \in D$.

REMARK 3. In a uniformly nonsquare space, for each $c \in\left(\varepsilon_{0}, 2\right]$ there always exists $s>1$ such that $(1-\delta(c / s)) s<1$.

Proof. Since $c>\varepsilon_{0}, \lim _{\varepsilon \rightarrow c-} \delta(\varepsilon)>0$. Thus $\lim _{s \rightarrow 1+}(1-\delta(c / s)) s=$ $1-\lim _{\varepsilon \rightarrow c-} \delta(\varepsilon)<1$. Therefore, there exists $s>1$ such that $(1-$ $\delta(c / s)) s<1$.

Theorem 3. Let $D$ be a convex subset of a uniformly convex Banach space $X$. Let $T: D \rightarrow D$ possess a nonempty compact fixed point set $A$. Suppose that there exists a neighborhood $U$ in $D$ of $A$ such that if $x \in U$ then $\|T x-x\| \geqq c d(x, A)$ for some constant $c \in(0,2]$, and such that $T$ is continuously Fréchet differentiable in $U$ with $\left\|T^{\prime} x\right\| \leqq 1$ if $x \in A$. Then theree exists $\rho>0$ such that if $x \in D$ and $d(x, A)<\rho$ then $d\left(F^{n} x, A\right) \rightarrow 0$.

Proof. By the remark above there exists $s>1$ such that $(1-\delta(c / s)) s<1$. Let $u \in A$. Since $T$ has a continuous Fréchet derivative in a neighborhood of $u$ and $\left\|T^{\prime} u\right\| \leqq 1$, there exists a neighborhood $U_{u}$ in $D$ of $u$ such that if $x \in U_{u}$ then $\|T x-u\|=$ $\|T x-T u\| \leqq s\|x-u\|$. Letting $V=U \cap \bigcup_{u \in A} U_{u}$ and choosing $\rho>0$ such that if $d(x, A)<\rho$ then $x \in V$, the hypotheses of Theorem 2 are satisfied. Therefore $d\left(F^{n} x, A\right) \rightarrow 0$, for each $x \in D$ with $d(x, A)<\rho$.

3. Some examples. Let $D$ be a closed convex subset of a Banach space $X$. We consider first mappings $T: D \rightarrow D$ satisfying the condition

$$
\begin{gathered}
\|T x-T y\| \leqq \\
+a\|x-y\|+b[\|x-T x\|+\|y-T y\|] \\
+c[\|x-T y\|+\|y-T x\|]
\end{gathered}
$$

where $a, b$, and $c$ are nonnegative constants such that $a+2 b+2 c=1$. In particular if $b=c=0, T$ is a nonexpansive mapping, while if $b=1 / 2, T$ is of a class of mappings investigated by Kannan [10]. A general fixed point theorem in uniformly convex spaces for mappings satisfying condition (1) has recently been proved by Goebel, Kirk, and Shimi in [8]. We now obtain the following application of Theorem 2 to mappings of this type:

Theorem 4. Let $D$ be a nonempty, closed, bounded, and convex subset of a uniformly convex Banach space $X$ and let $T: D \rightarrow D$ be $a$ continuous mapping satisfying condition (1) above with $b \neq 0$. 
Then $T$ has a unique fixed point $u$, and $F^{n} x \rightarrow u$, for every $x \in D$.

Proof. By the fixed point theorem of [9] $T$ has at least one fixed point. If $T u=u$ and $T v=v$ and $u \neq v$, then by (1) $\|u-v\| \leqq$ $(a+2 c)\|u-v\|$, which implies that $b=0$, a contradiction. Thus $T$ has a unique fixed point which we denote $u$.

If $x \in D$, then since $T u=u$

$$
\begin{aligned}
\|T x-u\| & \leqq a\|x-u\|+b\|x-T x\|+c[\|x-u\|+\|u-T x\| \\
& \leqq(a+b+c)\|x-u\|+(b+c)\|u-T x\| .
\end{aligned}
$$

By combining terms we obtain for every $x \in D$

$$
\|T x-u\| \leqq\|x-u\| \text {. }
$$

If $x \in D$ we have by inequality (2) above that

$$
(1-c)\|T x-u\| \leqq(a+c)\|x-u\|+b\|x-T x\| .
$$

Thus

$$
\begin{aligned}
(1-c)[\|x-u\|-\|x-T x\|] & \leqq(1-c)\|T x-u\| \\
& \leqq(a+c)\|x-u\|+b\|x-T x\| .
\end{aligned}
$$

Collecting terms we obtain

$$
(1+b-c)\|x-T x\| \geqq(1-a-2 c)\|x-u\| .
$$

Since $1+b-c>0$ and $1-a-2 c>0$ we have for every $x \in D$

$$
\|x-T x\| \geqq \frac{1-a-2 c}{1+b-c}\|x-u\| .
$$

The conditions of Theorem 2 are now satisfied (for $s=1$ and for every $\rho>0$ ), and thus in view of Remarks 1 and 2 above $F^{n} x \rightarrow u$ for every $x \in D$.

As another example we consider strongly pseudo-contractive mappings. If $D$ is a convex subset of a Banach space $X$ and $C \subset D$, a mapping $T: D \rightarrow D$ is said to be strongly pseudo-contractive relative to $C$ [7] if for each $x \in X$ and $r>0$ there exists a number $a_{r}(x)<1$ such that $\|x-y\| \leqq \alpha_{r}(x)\|(1+r)(x-y)-r(T x-T y)\|$, for every $y \in C$. It is easily seen that if $T$ has a fixed point $u \in C$, then $u$ is the only fixed point of $T$. Conditions for the existence of fixed points for such mappings are given in [7]. The following theorem gives conditions under which strongly pseudo-contractive mappings satisfy condition (i) of Theorem 2.

Theorem 5. Let $D$ be a convex subset of a Banach space $X$ 
and let $T: D \rightarrow D$ be strongly pseudo-contractive relative to $C$. If $T$ has a fixed point $u \in C$, and if for some $r>0 \lim \sup _{x \rightarrow u} \alpha_{r}(x)<1$, then there exists $c>0$ and an open ball $S(u, \varepsilon)$ of radius $\varepsilon$ about $u$ such that if $x \in D \cap S(u, \varepsilon)$ then $\|x-T x\| \geqq c\|x-u\|$.

Proof. Since lim $\sup _{x \rightarrow u} \alpha_{r}(x)<1$, there exists an open ball $S(u, \varepsilon)$ of radius $\varepsilon$ about $u$ and a constant $k \in(0,1)$ such that if $x \in D \cap S(u, \varepsilon)$ then $\alpha_{r}(x) \leqq k$. Let $c=(1-k) /(k r)$. Then $\left(1-\alpha_{r}(x)\right) /\left(\alpha_{r}(x) r\right) \geqq c$ for each $x \in D \cap S(u, \varepsilon)$. Since $T u=u$, for each $x \in D \cap S(u, \varepsilon)$

$$
\begin{aligned}
\|x-u\| \leqq \alpha_{r}(x) \| & (1+r)(x-u)-r(T x-u) \| \\
& =\alpha_{r}(x)\|r(x-T x)+(x-u)\| \\
& \leqq \alpha_{r}(x) r\|x-T x\|+\alpha_{r}(x)\|x-u\|,
\end{aligned}
$$

yielding

$$
\frac{1-\alpha_{r}(x)}{\alpha_{r}(x) r}\|x-u\| \leqq\|x-T x\|
$$

Thus

$$
c\|x-u\| \leqq\|x-T x\|
$$

for every $x \in D \cap S(u, \varepsilon)$.

\section{REFERENCES}

1. F. E. Browder, Convergence theorems for sequences of nonlinear operators in Banach spaces, Math. Zeit., 100 (1967), 201-225.

2. F. E. Browder and W. V. Petryshyn, The solution by iteration of nonlinear functional equations in Banach spaces, Bull. Amer. Math. Soc., 72 (1966), 571-575.

3. J. B. Diaz and F. T. Metcalf, On the structure of the set of subsequential limit points of successive approximations, Bull. Amer. Math. Soc., 73 (1967), 516-519.

4. M. Edelstein, A remark on a theorem of M. A. Krasnoselskii, Amer. Math. Monthly, 73(1966), 509-510.

5. M. Fréchet, Sur les fonctionelles continues, Ann. École Normale, 27 (1910), 193-216.

6. M. Furi and A. Vignoli, $A$ remark about some fixed point theorems, Boll. Un. Mat. Ital., (4) 3 (1970), 197-200.

7. J. A. Gatica and W. A. Kirk, Fixed-point theorems for lipschitzian pseudo-contractive mappings, Proc. Amer. Math. Soc., (to appear).

8. K. Goebel, W. A. Kirk, and Tawfik N. Shimi, A fixed point theorem in uniformly convex spaces, Boll. Un. Mat. Ital., (to appear).

9. V. I. Gurarii, Differential properties of the convexity moduli of Banach spaces, Mat. Issled., 2 (1967), vyp. 1, 141-148.

10. R. Kannan, Some results on fixed points-III, Fund. Math., 70 (1971), 169-177.

11. M. A. Krasnoselskii, Two remarks on the method of successive approximations, Uspehi Mat. Nauk., (N. S.) 63 (1955), 123-127.

12. C. L. Outlaw, Mean value iteration of nonexpansive mappings in a Banach space, Pacific J. Math., 30 (1969), 747-750.

13. W. V. Petryshyn, Construction of fixed points of demi-compact mappings in Hilbert spaces, J. Math. Anal. Appl., 14 (1966), 276-284. 
14. H. Schaeffer, Über die Methode suksessiver Approximation, Jber. Deutsch. Math. Verein., 59 (1957), 131-140.

Received December 18, 1972 and in revised form March 1, 1974. This paper is essentially a portion of the author's University of Iowa doctoral dissertation, written under the supervision of Professor W. A. Kirk.

\section{The UnIVERSITY OF IowA}

Current Address:

Department of Mathematics

The University of Nebraska-Lincoln

Lincoln, Nebraska, 68508 


\section{PACIFIC JOURNAL OF MATHEMATICS}

\section{EDITORS}

RICHARD ARENS (Managing Editor)

University of California

Los Angeles, California 90024

R. A. Beaumont

University of Washington

Seattle, Washington 98105
J. DugundJI

Department of Mathematics

University of Southern California

Los Angeles, California 90007

D. Gilbarg and J. Milgram

Stanford University

Stanford, California 94305

\section{ASSOCIATE EDITORS}

E. F. BECKENBACH

B. H. NeUMANN

F. WOLF

K. YosHIDA

\section{SUPPORTING INSTITUTIONS}

UNIVERSITY OF BRITISH COLUMBIA

CALIFORNIA INSTITUTE OF TECHNOLOGY

UNIVERSITY OF CALIFORNIA

MONTANA STATE UNIVERSITY

UNIVERSITY OF NEVADA

NEW MEXICO STATE UNIVERSITY

OREGON STATE UNIVERSITY

UNIVERSITY OF OREGON

OSAKA UNIVERSITY
UNIVERSITY OF SOUTHERN CALIFORNIA

STANFORD UNIVERSITY

UNIVERSITY OF TOKYO

UNIVERSITY OF UTAH

WASHINGTON STATE UNIVERSITY

UNIVERSITY OF WASHINGTON

$\stackrel{*}{*} \stackrel{*}{*} \stackrel{*}{*}$ AMERICAN MATHEMATICAL SOCIETY




\section{Pacific Journal of Mathematics}

\section{Vol. 53, No. $1 \quad$ March, 1974}

Martin Bartelt, Strongly unique best approximates to a function on a set, and a finite

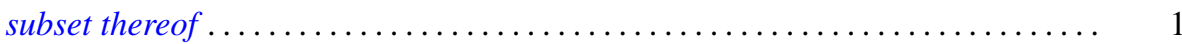

S. J. Bernau, Theorems of Korovkin type for $L_{p}$-spaces $\ldots \ldots \ldots \ldots \ldots \ldots \ldots \ldots \ldots$

S. J. Bernau and Howard E. Lacey, The range of a contractive projection on an

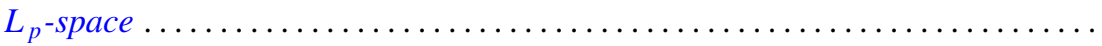

Marilyn Breen, Decomposition theorems for 3-convex subsets of the plane ......... Ronald Elroy Bruck, Jr., A common fixed point theorem for a commuting family of

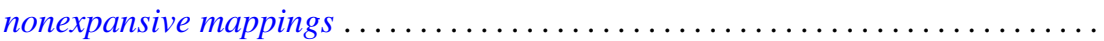

Aiden A. Bruen and J. C. Fisher, Blocking sets and complete $k$-arcs . . . . . . . 73

R. Creighton Buck, Approximation properties of vector valued functions . ......... 85

Mary Rodriguez Embry and Marvin Rosenblum, Spectra, tensor products, and

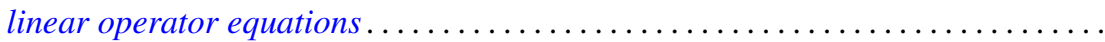

Edward William Formanek, Maximal quotient rings of group rings . . . . . . . . . 109

Barry J. Gardner, Some aspects of T-nilpotence . . . . . . . . . . . . . . . 117

Juan A. Gatica and William A. Kirk, A fixed point theorem for $k$-set-contractions

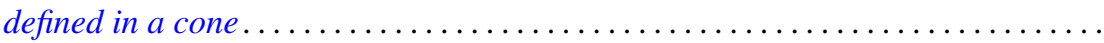

Kenneth R. Goodearl, Localization and splitting in hereditary noetherian prime

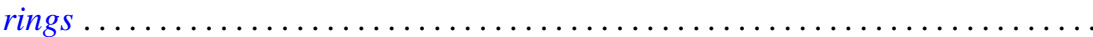

James Victor Herod, Generators for evolution systems with quasi continuous

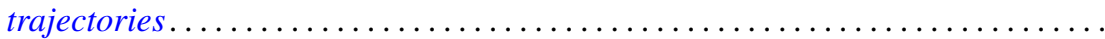

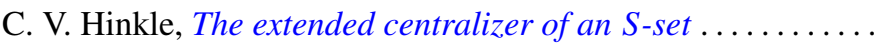

I. Martin (Irving) Isaacs, Lifting Brauer characters of p-solvable groups . . .

Bruce R. Johnson, Generalized Lerch zeta function ...........

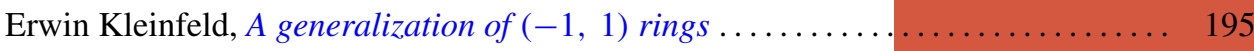

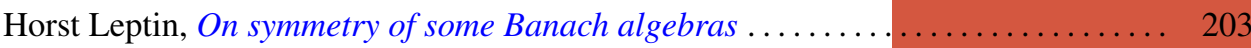

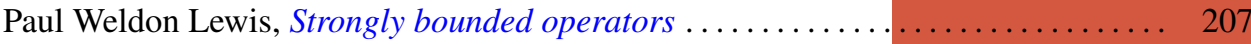

Arthur Larry Lieberman, Spectral distribution of the sum of self-adjoint

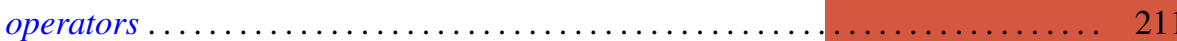

I. J. Maddox and Michael A. L. Willey, Continuous operators on paranormed spaces and matrix transformations

James Dolan Reid, On rings on groups ........................... 229

Richard Miles Schori and James Edward West, Hyperspaces of graphs are Hilbert cubes.

William H. Specht, A factorization theorem for p-constrained groups ...

Robert L Thele, Iterative techniques for approximation of fixed points of certain nonlinear mappings in Banach spaces ...............

Tim Eden Traynor, An elementary proof of the lifting theorem

Charles Irvin Vinsonhaler and William Jennings Wickless, Completely decomposable groups which admit only nilpotent multiplications .

Raymond O’Neil Wells, Jr, Comparison of de Rham and Dolbeault cohomology for

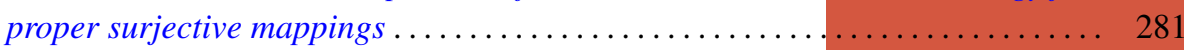

David Lee Wright, The non-minimality of induced central representations . . . . . 301 